\title{
Bonding in MgSi and Al-Mg-Si compounds relevant to Al-Mg-Si alloys
}

\author{
Anders G. Frøseth ${ }^{*}$ and Ragnvald Høier \\ Norwegian University of Science and Tecnology (NTNU), N-7034 Trondheim, Norway \\ Peter M. Derlet \\ Paul Scherrer Institute, CH-5232 Villigen PSI, Switzerland
}

Sigmund J. Andersen and Calin D. Marioara

SINTEF Materials Technology, Applied Physics, N-7050 Trondheim, Norway

(Received 17 December 2002; published 19 June 2003)

\begin{abstract}
The bonding and stability of $\mathrm{MgSi}$ and $\mathrm{Al}-\mathrm{Mg}-\mathrm{Si}$ compounds relevant to Al-Mg-Si alloys is investigated with the use of (linearized) augmented plane-wave + (local-orbitals) density-functional theory calculations. We show that the $\beta$ and $\beta^{\prime \prime}$ phases found in the precipitation sequence are characterized by the presence of covalent bonds between Si-Si nearest-neighbor pairs and covalent/ionic bonds between $\mathrm{Mg}$-Si nearest-neighbor pairs. We then investigate the stability of two recently discovered precipitate phases, $U 1$ and $U 2$, both containing $\mathrm{Al}$ in addition to $\mathrm{Mg}$ and $\mathrm{Si}$. We show that both phases are characterized by tightly bound $\mathrm{Al}-\mathrm{Si}$ networks, made possible by a transfer of charge from the $\mathrm{Mg}$ atoms.
\end{abstract}

DOI: 10.1103/PhysRevB.67.224106

PACS number(s): 71.20.Gj

\section{INTRODUCTION}

Precipitation or age-hardened alloys are today one of the most important alloy types in industry. In the Al-Mg-Si alloy system, $\mathrm{Mg}-\mathrm{Si}$ and $\mathrm{Al}-\mathrm{Mg}-\mathrm{Si}$ precipitates formed during specific-heat treatments give rise to a very significant increase in strength. The precipitation sequence is generally accepted to be

$$
\mathrm{SSSS} \rightarrow \mathrm{Mg} / \mathrm{Si} \text { clusters } \rightarrow \mathrm{GPZ} \rightarrow \beta^{\prime \prime} \rightarrow \beta^{\prime} \rightarrow \beta,
$$

where GPZ refers to a Guinier-Preston zone and SSSS refers to a supersaturated solid solution. Very little is known about the early stages of the precipitation process. However, it is believed that when the SSSS is heat treated, $\mathrm{Mg}$ and $\mathrm{Si}$ atoms quickly diffuse substitutionally to form small clusters due to the large amount of quenched-in vacancies ${ }^{1}$ (a large part of the vacancies move to interfaces such as surfaces and grain boundaries in the later stages of the heat treatment). Although the details are hard to investigate experimentally, several studies of such clustering have been carried out using atom probe microscopy. ${ }^{2,3}$ The first phase which can be resolved using high-resolution electron microscopy is the GPZ. From this, a model of its crystal structure has recently been proposed. ${ }^{4}$ The structure of the proceeding phase, $\beta^{\prime \prime}$, was also solved using electron microscopy techniques, ${ }^{5}$ a result which has later been supported by $a b$ initio calculations. ${ }^{6}$

Earlier it was believed that the GPZ, $\beta^{\prime \prime}$, and $\beta$ phases all had the stoichiometry of the $\beta$ phase, $\mathrm{Mg}_{2} \mathrm{Si}$, and that alloys should be optimized accordingly. Thus, the terminal $\beta$ phase was of primary importance. Later, however, it had been confirmed that the $\beta^{\prime \prime}$ gives a greater contribution to the hardness due to its semicoherent interface with the aluminum matrix and needlelike shape, which is more effective for dislocation pinning. ${ }^{7}$ The $\beta^{\prime \prime}$ stoichiometry has been shown to be $\mathrm{Mg}_{5} \mathrm{Si}_{6} \cdot 5$
Recently, several additional phases have been identified experimentally, ${ }^{8-10}$ giving the extended precipitation sequence

$$
\begin{aligned}
\mathrm{SSSS} & \rightarrow \mathrm{Mg} / \mathrm{Si} \text { clusters } \\
& \rightarrow \mathrm{GPZ} \rightarrow \beta^{\prime \prime} \rightarrow\left(\beta^{\prime}+U 2+U 1+B^{\prime}\right) \rightarrow \beta .
\end{aligned}
$$

In Ref. 8 the phases $U 1, U 2$, and $B^{\prime}$ are referred to as types $A, B$, and $C$, respectively. These three phases, in addition to $\beta^{\prime}$, are often grouped together since little is known about their interdependence. However, it is believed that the peak of concentration with respect to time for each of these structures follows the ordering given by the above precipitation sequence. ${ }^{8}$ They all form relatively late in the precipitation sequence usually at temperatures in the range $200^{\circ} \mathrm{C}-300^{\circ} \mathrm{C}$, and in Si-rich alloy compositions.

It has been considered a general rule of thumb that successful aluminum precipitation hardening alloys contain secondary and ternary alloying elements which are larger and smaller than aluminum. ${ }^{11}$ Now, the concept of atom size in this context must be based on the type of bonding involved. One can have either ionic, metallic, or covalent radii for the constituent elements, giving dramatically different values for atomic size. ${ }^{12}$ It is clear that when studying the electronic density of compound structures this type of concept may lead to an oversimplification. It it therefore interesting to carry out a theoretical study of the electronic structure and bonding characteristics of the relevant phases with respect to their relative stability. This is the purpose of the present work, where we employ full potential $a b$ initio methods based on density-functional theory (DFT) to investigate the bonding within the above-mentioned structures. In Sec. II we describe the linear augmented plane-wave + local-orbitals approach $[(\mathrm{L}) \mathrm{APW}+(\mathrm{lo})]$, used for all calculations. Section III describes the results obtained for the three models of precipi- 
tate phases containing only $\mathrm{Mg}$ and $\mathrm{Si}\left(\beta^{\prime \prime}, \beta^{\prime}\right.$, and $\left.\beta\right)$, and $\mathrm{Sec}$. IV deals with the phases containing $\mathrm{Al}, \mathrm{Mg}$, and $\mathrm{Si}(U 1$ and $U 2$ ).

\section{METHOD}

The $a b$ initio calculations were performed using WIEN2K, a program package implementing the full potential (L)APW + (lo) DFT method. ${ }^{13}$ The augmented plane-wave (APW) approach $+\left(\right.$ lo) method ${ }^{14}$ differs from the LAPW method in the linearization of the APW's. In Slater's original APW method ${ }^{15}$ the unit cell is partitioned into nonoverlapping atomic spheres and an interstitial region. The basis functions are plane waves for the interstitial region and radial wave functions within the atomic spheres. In the LAPW method the basis functions inside the spheres are linearized with respect to the energy $E_{l}$ :

$$
\psi_{\boldsymbol{k}_{n}}(\mathbf{r})=\sum_{l m}\left[A_{l m, \mathbf{k}_{n}} u_{l}\left(r, E_{l}\right)+B_{l m, \mathbf{k}_{n}} \dot{u}_{l}\left(r, E_{l}\right)\right] Y_{l m}(\hat{\mathbf{r}}),
$$

where $u_{l}\left(r, E_{l}\right)$ are radial functions and $Y_{l m}(\boldsymbol{r})$ are spherical harmonics. $\dot{u}_{l}\left(r, E_{l}\right)$ is the energy derivative of $u_{l}\left(r, E_{l}\right)$. $A_{l m, \boldsymbol{k}_{n}}$ and $B_{l m, \boldsymbol{k}_{n}}$ are determined by matching the above basis to the value and derivative of the plane waves for each $k$ vector at the sphere boundary. An alternative way for linearizing is the APW+lo method. One starts with the original APW's and adds local orbitals to obtain the variational flexibility in the basis functions,

$$
\begin{gathered}
\psi_{\boldsymbol{k}_{\boldsymbol{n}}}(\boldsymbol{r})=\sum_{l m}\left[A_{l m, \boldsymbol{k}_{n}} u_{l}\left(r, E_{l}\right)+\phi_{l o}\right] Y_{l m}(\hat{\boldsymbol{r}}), \\
\phi_{l o}=B_{l m} u_{l}\left(r, E_{l}\right)+C_{l m} \dot{u}_{l}\left(r, E_{l}\right) .
\end{gathered}
$$

At first sight this looks very similar to the LAPW basis. However, the $B_{l m}$ and $C_{l m}$ are no longer dependent on the wave vector and are determined by the requirement that the local orbital is zero at the sphere boundary and normalized. The great advantage of this scheme is that the calculations converge to results almost identical with those of the LAPW method but for dimensioning parameters, which effectively leads to a smaller basis set. ${ }^{16}$ The WIEN2K code uses a mixed APW + lo/LAPW basis set, exploiting the advantages of both methods.

To make the results for the different structures comparable, we used the same set of APW + (lo) parameters for all calculations: $R_{m t}=2.1$ bohr, $R_{m t} K_{\max }=7$ and $G_{\max }$ $=14 \mathrm{Ry}^{1 / 2}$. Here, $R_{m t}$ is the muffin-tin radius, $K_{\max }$ is the plane-wave cutoff, and $G_{\max }$ is the maximum Fourier component of the electron density. For all calculations we used the modified tetrahedron method ${ }^{17}$ for Brillouin-zone integrations. All $k$-point meshes were checked for convergence. Thus in general, the highly symmetric structures (such as bulk $\mathrm{Al}, \mathrm{Si}$, and $\mathrm{Mg}$ ) with few symmetrically inequivalent atoms in the unit cell require a denser $k$-point mesh than the precipitate phases with larger unit cells and a lower symme-

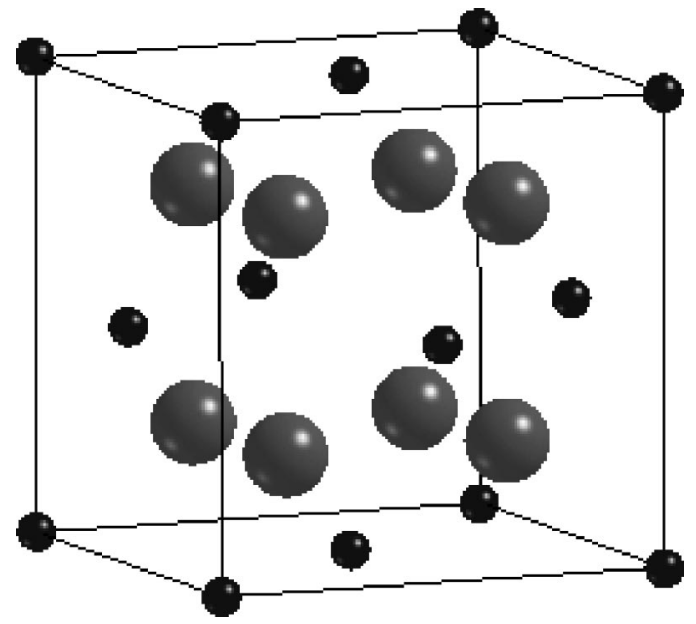

FIG. 1. Conventional unit cell for fluorite $\mathrm{Mg}_{2} \mathrm{Si}$, equivalent to the $\beta$ phase in the $\mathrm{Al}-\mathrm{Mg}$-Si precipitaion sequence. The large spheres are $\mathrm{Mg}$ atoms and the smaller ones are $\mathrm{Si}$.

try. For the exchange-correlation potential we used the generalized gradient approximation of Perdew et al. ${ }^{18}$

\section{MgSi PHASES}

\section{A. $\boldsymbol{\beta}$}

The $\beta$ phase (fluorite $\mathrm{Mg}_{2} \mathrm{Si}$ ) is the terminal equilibrium structure of the precipitation sequence. It has a fcc primitive unit cell [space group $F m \overline{3} m$ (225)], with an experimental lattice parameter $a=6.39 \AA .{ }^{4}$ It forms precipitates of a platelike or cubic shape up to $20 \mu \mathrm{m}$ in diameter. Its interface with the $\mathrm{Al}$ matrix is fully incoherent. ${ }^{4}$ The conventional unit cell, containing eight $\mathrm{Mg}$ atoms and four $\mathrm{Si}$ atoms, is shown in Fig. 1. As can be seen, each of the Si atoms in the structure has eight $\mathrm{Mg}$ nearest neighbors, giving each $\mathrm{Mg}$ atom four $\mathrm{Si}$ nearest neighbors at the same distance. The Si atoms are arranged as an fcc lattice interpenetrated by a sc $\mathrm{Mg}$ lattice.

Several ab initio studies of the bonding in fluorite $\mathrm{Mg}_{2} \mathrm{Si}$ have been carried out in the past. ${ }^{19-21}$ However, to our knowledge, none of these involved the LAPW or (L)APW + (lo) DFT method. For our calculations we use the experimentally observed lattice constant for this phase in the Al matrix: $6.39 \AA$. Performing a volume relaxation, this value differed by only $0.25 \%$ from the calculated optimized value $6.37 \AA$, and by $0.6 \%$ from the experimental value for bulk $\mathrm{Mg}_{2} \mathrm{Si}, 6.338 \AA .22$ The calculated bulk modulus, derived from a second-order Birch fit, was $54.3 \mathrm{GPa}$, compared to 59 GPa from experiment. ${ }^{22}$ Using the 6.39- $\AA$ lattice constant the nearest-neighbor (nn) Mg-Si distance is $2.77 \AA$, the $\mathrm{Si}-\mathrm{Si} n$ distance is $4.51 \AA$, and the $\mathrm{Mg}-\mathrm{Mg} n$ distance is $3.29 \AA$.

Past linear-combination-of-atomic-orbitals Hartree-Fock and DFT pseudopotential calculations ${ }^{19,21}$ indicate considerable charge transfer from the electropostive $\mathrm{Mg}$ atoms to the electronegative $\mathrm{Si}$ atoms, resulting in a partly ionic $\mathrm{Si}-\mathrm{Mg}$ bond for the $\beta$ phase. This result is also supported by the present work. Figure 2 displays the bonding charge density for the (101) plane of Fig. 1. We define the bonding charge 


\section{Bonding Charge Density for Fluorite}

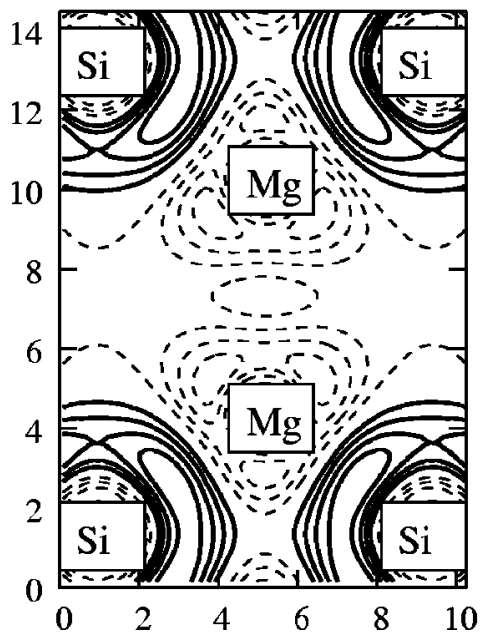

FIG. 2. Bonding charge density for the (101) plane. The two central peaks are $\mathrm{Mg}$ atoms. The four corner peaks are $\mathrm{Si}$ atoms. Thick lines represent positive contour lines and thin dashed lines represent negative contour lines.

density as the difference between the converged valence charge density from DFT and the charge density derived from the isolated neutral atoms. Thus the bonding charge density indicates the charge transfer resulting from the converged electronic structure. In Fig. 2, the thick lines represent positive contours corresponding to charge transfer to the region, while the thinner dashed lines represent negative contours corresponding to charge transfer away from the region. The concentration of thick lines around the $\mathrm{Si}$ atoms thus displays a net buildup of charge around the $\mathrm{Si}$ atoms counterbalanced by a net reduction of charge around the central $\mathrm{Mg}$ atoms, indicating that some ionicity is indeed at play.

Figure 3 displays the corresponding total and partial electronic densities of states for the $\beta$ phase. Here the partial density of states (DOS) represents the "muffin-tindecomposed" DOS for both the Mg and Si atoms, in which

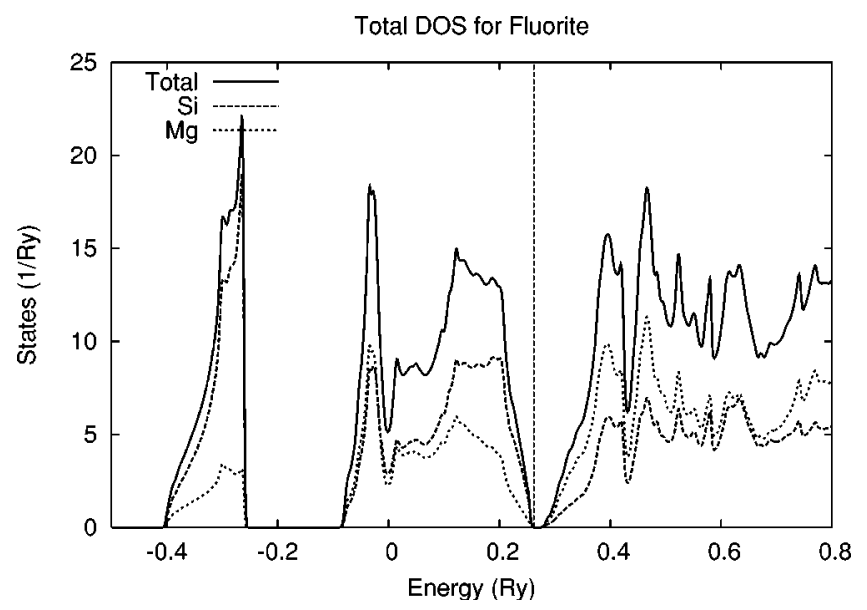

FIG. 3. Muffin-tin-decomposed DOS for the $\beta$ phase. Note that the atomic Mg DOS is half the magnitude of the total Mg DOS. The vertical line represents the Fermi level. the occupied states are projected onto the muffin-tin eigenvectors (see Sec. II) of the particular atom. In this way, some information can be gained regarding the local DOS at each atom, however, such a procedure is not complete since the interstitial region cannot be locally resolved. On the other hand, the total DOS represents the DOS derived from all the "muffin-tin-decomposed" densities of states and the interstitial DOS of the entire computational cell. Note that the calculation is based on the primitive unit cell, containing one symmetrically inequivalent $\mathrm{Si}$ atom and two symmetrically inequivalent $\mathrm{Mg}$ atoms, thus the partial $\mathrm{Mg}$ DOS contains the contribution for two $\mathrm{Mg}$ atoms, and the Si DOS the contribution from one $\mathrm{Si}$ atom.

When decomposing the atomic DOS, we project out the $d$ states in addition to the $s$ and $p$ valence states, in order to make sure that we have completely specified the orbital contributions to the total atomic DOS. This is especially important for the phases containing aluminum since previous calculations have shown that the band structure of fcc $\mathrm{Al}$ contains bands with a non-negligible contribution from $d$ states below the Fermi level around the $\Gamma$ point. ${ }^{23}$

A general feature of the total and partial densities of states in Fig. 3 is the two broad bands below the Fermi energy (indicated by the horizontal line at $0.26 \mathrm{Ry}$ ) separated by an energy of approximately $0.4 \mathrm{Ry}$. That the occupancy is dominated by Si states, where the partial Mg DOS represents the two inequivalent $\mathrm{Mg}$ atoms, is a further indication of the presence of ionicity whereby the $\mathrm{Mg}$ has simply donated electrons to the $\mathrm{Si}$. In addition this phase has a band gap. The magnitude of the gap at the $\Gamma$ point is $0.13 \mathrm{Ry}(1.77 \mathrm{eV})$, which is somewhat smaller than the experimental value of $2.27 \mathrm{eV}$ for a lattice constant of $6.338 \AA \AA^{24}$

Figures 4(a) and 4(b) now display the $s, p$, and $d$ decomposed partial densities of states for both $\mathrm{Si}$ and the two inequivalent $\mathrm{Mg}$ atoms. In this case, the total DOS represents the total muffin-tin-decomposed DOS for the particular atom, that is, the sum of the $s, p$, and $d$ partial densities of states. Inspection of Fig. 4(a) reveals that the lower band consists of $s$ states whereas the upper band consists of predominantly $p$ states with a little $s$-state character. For the case of the Mg, Fig. 4(b), the DOS below the Fermi level largely mimics that of $\mathrm{Si}$ apart from both occupied bands being of mixed $s$ and $p$ character.

Insight into the general features of the densities of state shown in Fig. 4 can be understood from the perspective of beginning with pure fcc Si with a lattice constant of $6.39 \AA$, giving a rather large nn Si-Si separation of $4.52 \AA$. For such a system there can be no strong hybridization between the atomic valence $s$ and $p$ states, maintaining a gap of approximately 0.3 Ry in the corresponding DOS (not shown). The $s$ and $p$ band centers differ by about $0.4 \mathrm{Ry}$, which is not so dissimilar from the 0.49-Ry difference between the isolated atom $3 s$ and $3 p$ valence states. With the addition of the interpenetrating cubic array of $\mathrm{Mg}$ atoms, both bands broaden, reducing the gap to about 0.2 Ry. Thus in Fig. 4(a), the dominant $s$ character of the filled lower band and the dominant $p$ character of the upper filled band arise from the strong on-site Si orthogonality requirement, whereas in Fig. 4 the mixed $s$ and $p$ character of the corresponding Mg bands 


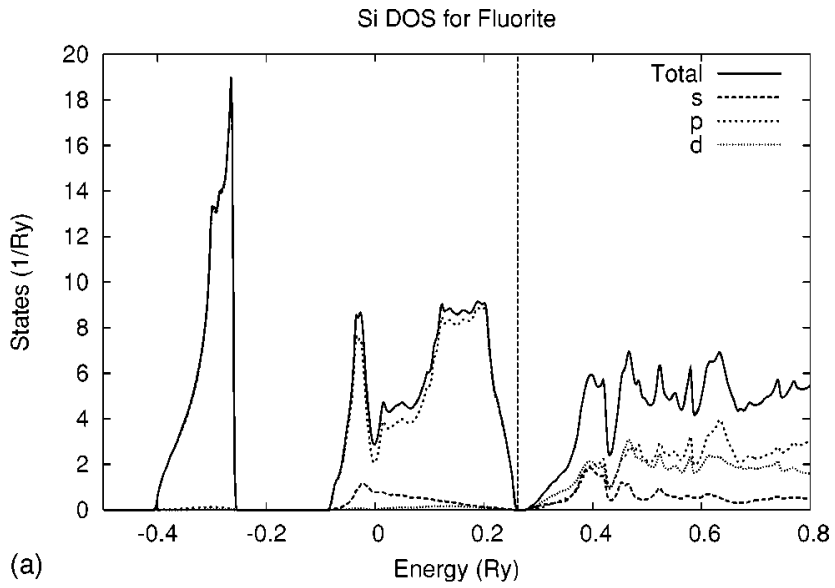

(a)

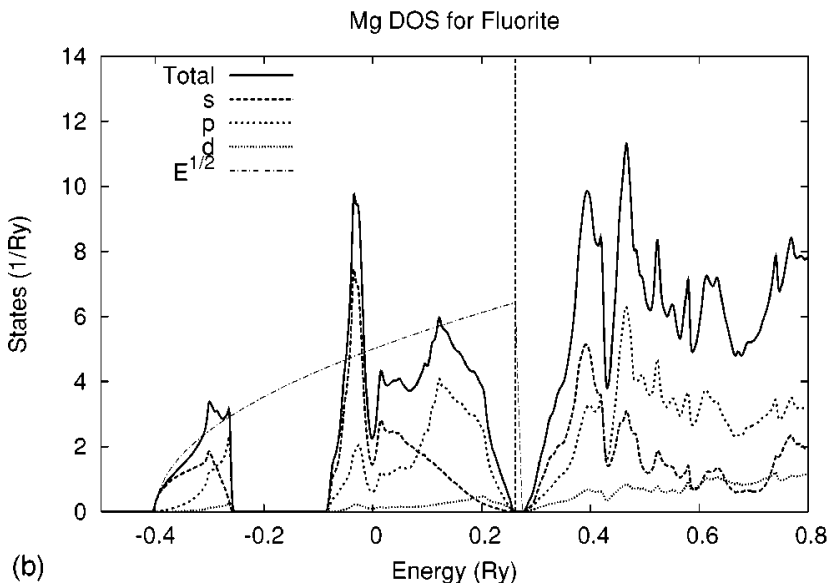

FIG. 4. (a) $\mathrm{Si}$ and (b) Mg muffin-tin-decomposed densities of state for the $\beta$ phase. Note that for the Si DOS, the $s$ curve is practically superimposed on the total curve for the lower band in the range -0.4 to $-0.25 \mathrm{Ry}$. The scaled square-root curve is shown for comparison.

arises from the Mg-Si $s$ and $p$ matrix interaction elements. We note that the corresponding heights of the Mg total DOS are significantly less than the Si DOS, following approximately the square-root dependence of a metallic DOS. Thus, through charge transfer to the $\mathrm{Si}$, the $\mathrm{Mg}$ plays the role of "strengthening" the Si backbone lattice, providing an explanation of the origin of the $\beta$ phase band gap through the pulling down of the excited $s, p$, and $d$ states of atomic Si.

\section{B. $\boldsymbol{\beta}^{\prime \prime}$}

The $\beta^{\prime \prime}$ phase has a base-centered-monoclinic conventional unit cell (space group $C 2 \mathrm{~m}$ ) with experimental lattice parameters $a=15.16 \AA, b=6.74 \AA, c=4.05 \AA$, and $\gamma_{a b}$ $=105.3^{\circ} .5$ Figure 5 displays the conventional cell for two viewing orientations. This phase forms precipitates of a needlelike shape, typically with a thickness of 30-50 $\AA$ and a length of 300-400 $\AA$. The needle length, which is along the $\langle 001\rangle$ direction of the $\beta^{\prime \prime}$-phase unit cell, runs parallel to the $\langle 001\rangle$ direction of the aluminum matrix. For the present work we use the experimentally derived lattice parameters and the relaxed atomic positions of the inequivalent $\mathrm{Si}$ and $\mathrm{Mg}$ atoms by minimizing the forces by a Newton-Coates

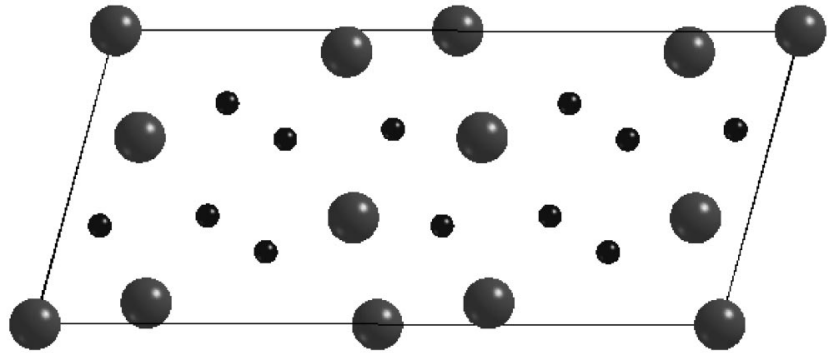

(a)

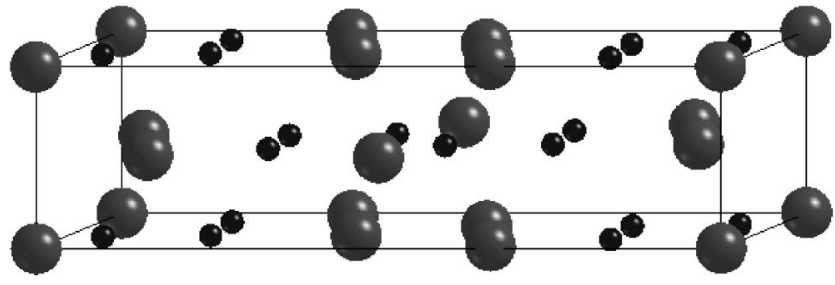

(b)

FIG. 5. Conventional unit cell for $\beta^{\prime \prime}$ seen from (a) $\langle 001\rangle$ direction, and (b) slightly away from the $\langle 010\rangle$ Cartesian direction. The large circles represent $\mathrm{Mg}$ and the small circles $\mathrm{Si}$.

procedure with respect to the $C 2 / \mathrm{m}$ space group. The resulting inequivalent atomic coordinates are listed in Table I. The given space group of this phase was first solved by highresolution electron microscopy techniques ${ }^{5}$ and later supported by full potential linear argumented plane-wave DFT calculations. ${ }^{6}$ In this paper we elaborate further on the electronic structure calculations presented by Derlet et $a{ }^{6}{ }^{6}$ by also analyzing the partial DOS.

Figure 6 displays the bonding charge-density contour plot for the (002) plane. A dominant feature is the concentration of charge between the Si nearest neighbors, and to a lesser extent, between the $\mathrm{Si}$ and $\mathrm{Mg}$ nearest neighbors, indicating that covalency is at play in this system. ${ }^{6}$ Such charge transfer to the bonding regions originates from the core regions of both the $\mathrm{Si}$ and $\mathrm{Mg}$ atoms, in addition to the homogeneous interstitial region between the $\mathrm{Mg}$ atoms. The depletion of charge from the $\mathrm{Mg}$ is comparable to that seen in the $\beta$ phase, indicating that for this system both ionicity and covalency is present in the bonding. The nearest-neighbor distance range in this structure is $2.39-2.53 \AA$ for $\mathrm{Si}-\mathrm{Si}$ and 2.61-2.84 $\AA$ for Si-Mg. This is not dissimilar to the nearestneighbor distance of $2.33 \AA$ in covalently bonded diamond cubic $\mathrm{Si}$ and $2.76 \AA$ in the covalent/ionic equilibrium $\beta$

TABLE I. Relaxed fractional coordinates for the inequivalent atomic positions of the $\beta^{\prime \prime}$ phase.

\begin{tabular}{lccc}
\hline \hline Atom & $a$ & $b$ & $c$ \\
\hline Mg1 & 0.0 & 0.0 & 0.0 \\
Mg2 & $0.346(1)$ & $0.071(9)$ & 0.0 \\
Mg3 & $0.421(6)$ & $0.063(6)$ & 0.0 \\
Si1 & $0.055(7)$ & $0.662(7)$ & 0.0 \\
Si2 & $0.194(4)$ & $0.250(5)$ & 0.0 \\
Si3 & $0.209(1)$ & $0.627(5)$ & 0.0 \\
\hline
\end{tabular}




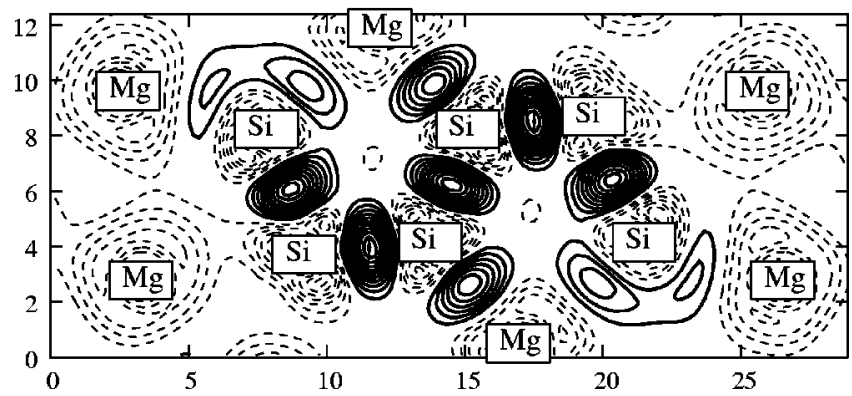

FIG. 6. Bonding charge density for the (002) plane section of the $\beta^{\prime \prime}$ structure. Thick contour lines represent a positive charge transfer, while thin dashed lines represent a negative charge transfer.

phase. Moreover, one of the inequivalent $\mathrm{Si}$ atoms is $s p^{3}$ (tetrahedrally) coordinated and another is $s p^{2}$ coordinated. ${ }^{6}$

Figure 7 displays the total DOS (including the muffin-tin and interstitial regions) for the $\beta$ phase. Unlike the $\beta$ phase, there is no band gap. However, depressions can be identified at -0.1 and $0.4 \mathrm{Ry}$, reminiscent of the gaps seen in Fig. 3. By inspection of the partial DOS for each inequivalent atom we find that for the $\mathrm{Si}$ atoms there is a dominant $s$ character for the lower-energy states $(<-0.2 \mathrm{Ry})$, whereas, at about $0.2 \mathrm{Ry}$, the $p$ character dominates. In between these regimes, a mixture of $p$ and $s$ character exists, indicating strong hybridization. Indeed Fig. 8(a) displays the partial DOS for Si2, which from past work is locally $s p^{3}$ coordinated, ${ }^{6}$ showing approximate correspondence with the diamond cubic $\mathrm{Si}$ DOS. ${ }^{25}$ In particular the dominant $s$ character of the $L_{2^{\prime}}$, the $s$ and $p$ character of the $L_{1}$, and the dominant $p$ character of $X_{4}$ are the high-symmetry points. Alternatively, Fig. 8(b) shows the partial DOS for Mg3, which from charge-density profile analysis ${ }^{6}$ is in a homogeneous metallic environment, displaying an approximate shifted metallic square-root behavior.

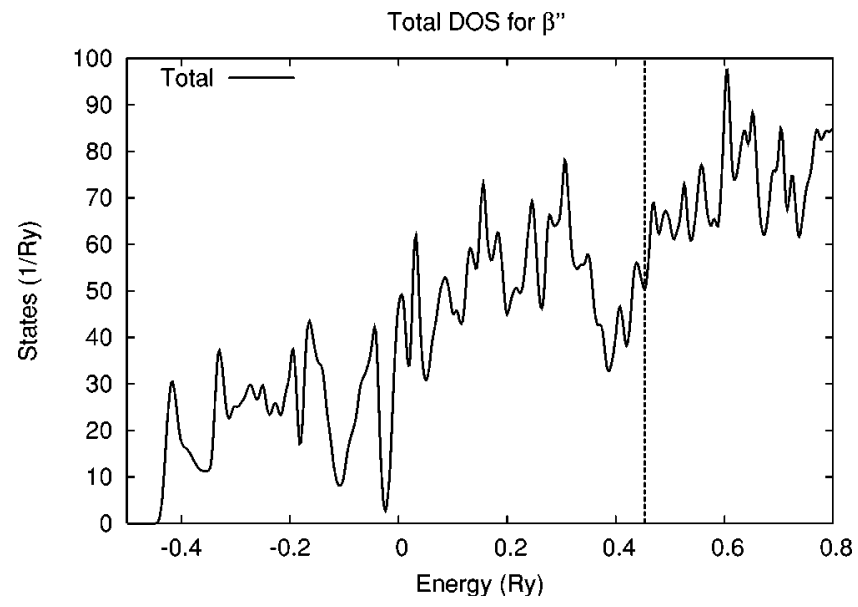

FIG. 7. Total DOS for the $\beta^{\prime \prime}$ phase. The vertical line represents the Fermi level.
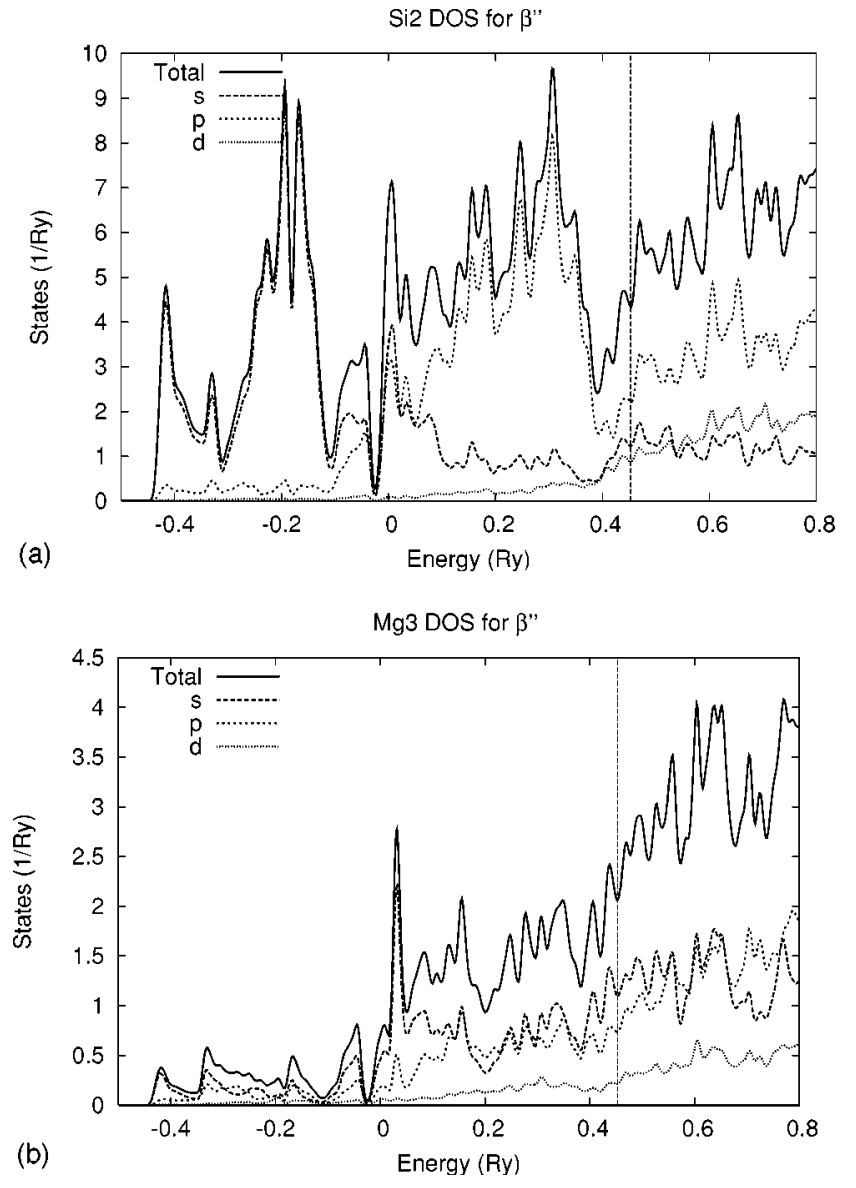

FIG. 8. Partial DOS for the (a) $\mathrm{Si} 2$ and (b) $\mathrm{Mg} 3$ (see Table I) atoms in the $\beta^{\prime \prime}$ phase.

\section{Al-Mg-Si PHASES}

\section{A. $U 1$}

The $U 1$ conventional/primitive unit cell is trigonal (space group $P \overline{3} m 1$ ) with experimentally derived lattice parameters $a=b=4.05 \AA$ and $c=6.74 \AA$. It contains one $\mathrm{Mg}$, two $\mathrm{Al}$, and two $\mathrm{Si}$ atoms, giving the formula $\mathrm{MgAl}_{2} \mathrm{Si}_{2}$. The unitcell and atomic positions are shown in Table II and Fig. 9. Experiments show that the $\langle 001\rangle$ direction of the $U 1$ unit cell runs parallel to the $\langle 310\rangle$ direction of the fcc Al matrix. ${ }^{9}$ The $U 1$ phase usually forms rodlike precipitates with a length of 50-500 nm and a width of approximately $50 \mathrm{~nm}$. Performing a volume relaxation, we found the calculated unit-cell equilibrium volume to differ by only $1 \%$ from the experimentally derived unit-cell volume. From a secondorder Birch fit we obtained a bulk modulus of $71 \mathrm{GPa}$.

TABLE II. Fractional coordinates for the inequivalent atomic positions of the $U 1$ phase Ref. 9.

\begin{tabular}{lccc}
\hline \hline Atom & $a$ & $b$ & $c$ \\
\hline $\mathrm{Mg}$ & 0.0 & 0.0 & 0.0 \\
$\mathrm{Al}$ & $1 / 3$ & $2 / 3$ & $0.632(8)$ \\
$\mathrm{Si}$ & $1 / 3$ & $2 / 3$ & $0.243(8)$ \\
\hline \hline
\end{tabular}



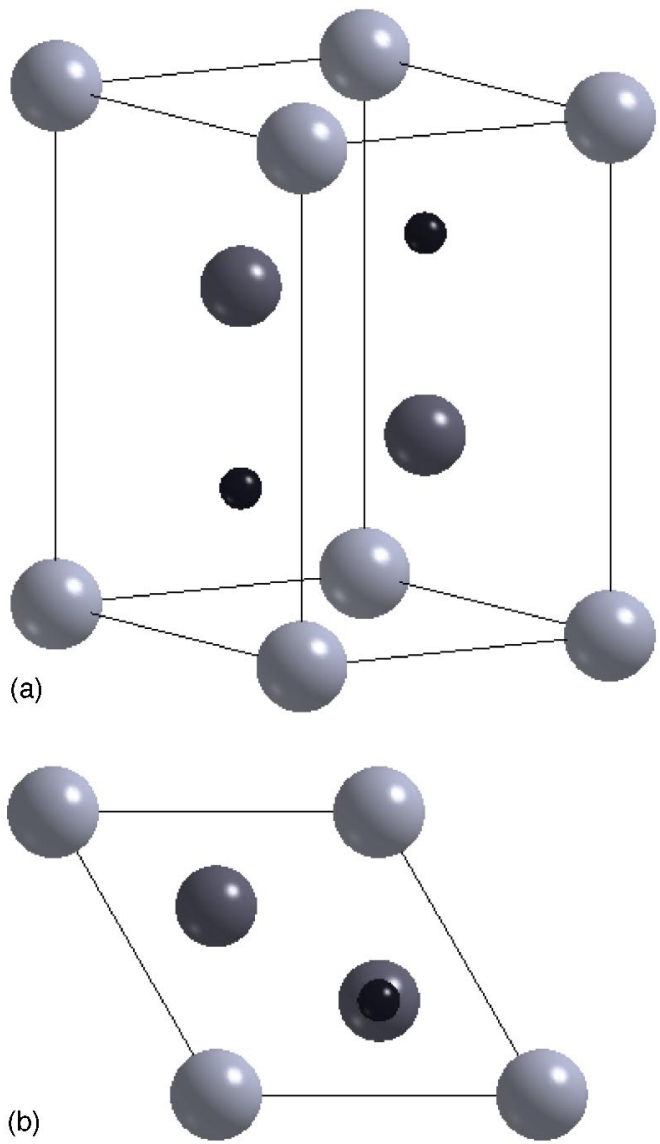

FIG. 9. $U 1$ conventional unit cell in the (a) perspective and (b) $\langle 001\rangle$ direction. The small black spheres are $\mathrm{Si}$ atoms, the large dark spheres $\mathrm{Al}$ atoms, and the large white spheres $\mathrm{Mg}$ atoms.

The $U 1$ phase can be categorized as belonging to a class of structures given the name of $\mathrm{CaAl}_{2} \mathrm{Si}_{2}$-type Zintl compounds. ${ }^{26}$ In Zintl compounds, the electropositive elements are thought of as merely electron donors to the electronegative elements which thereby are able to fulfill the octet rule. For $\mathrm{MgAl}_{2} \mathrm{Si}_{2}$ this implies that each $\mathrm{Mg}$ atom donates two electrons to $\mathrm{Al}_{2} \mathrm{Si}_{2}$ for each unit cell. This gives $\mathrm{Al}_{2} \mathrm{Si}_{2}^{2-}$, or two units of $\mathrm{AlSi}^{-}$which is isoelectronic to AlN, fulfilling the octet rule. The resulting layered structure is sketched in Fig. 10. $\mathrm{AlSi}^{-}$constitutes a double layer of tightly bound "chairlike" six-membered rings separated by layers of hexagonal $\mathrm{Mg}^{2+}$. In the $\mathrm{Al}-\mathrm{Si}$ network, each $\mathrm{Si}$ atom bonds to four $\mathrm{Al}$ atoms forming an umbrellalike structure, while each $\mathrm{Al}$ atom forms the more common tetrahedral structure with four nearest-neighbor $\mathrm{Si}$ atoms. The $\mathrm{Al}-\mathrm{Si}$ bond length within each AlSi layer is $2.48 \AA$, while the length of the $\mathrm{Al}-\mathrm{Si}$ bonds connecting the two $\mathrm{AlSi}^{-}$layers is $2.62 \AA$. The length of the $\mathrm{Mg}$-Si bond is $2.86 \AA$ (see below and Fig. 11), somewhat larger than the length of the partly ionic bond in the $\beta$ equilibrium structure, but similar to $\mathrm{Mg}-\mathrm{Si}$ bonds found in the $\mathrm{Mg}_{5} \mathrm{Si}_{6} \beta^{\prime \prime}$ phase. ${ }^{6}$

The calculated bonding charge density for the (110) plane is shown in Fig. 11. There is a clear concentration of charge between the $\mathrm{Al}$ and $\mathrm{Si}$ atoms, indicating strong $\mathrm{Al}-\mathrm{Si}$ bond-

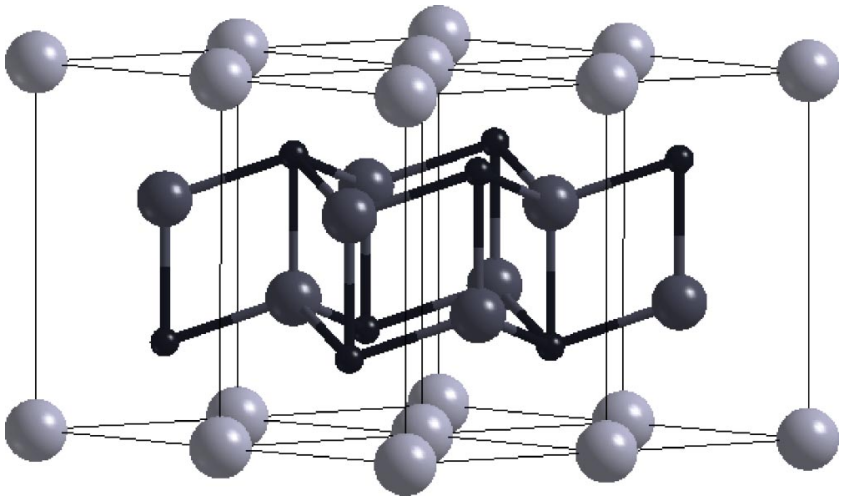

FIG. 10. $U 1$ bonding network

ing. There is also a small buildup of charge between the $\mathrm{Si}$ and corner $\mathrm{Mg}$ atoms which constitutes a coupling between $\mathrm{Mg}^{2+}$ and $\mathrm{AlSi}^{-}$layers.

Evidence of the layered structure can also found in the DOS. Figures 12 and 13 show the muffin-tin-decomposed total and partial densities of states. The total DOS below the Fermi level is characterized by two broad bands, separated by a 0.1-Ry band gap [Fig. 12(a)]. It is also evident that the major contribution to the total DOS stems from the $\mathrm{Al}$ and $\mathrm{Si}$ states. This is an indication that the $\mathrm{Mg}$ donates charge to the $\mathrm{Al}-\mathrm{Si}$ network and is not strongly involved in the electronic bonding. Furthermore, the Si states give a relatively larger contribution to the total DOS than do the Al states. From the angular decomposed Si DOS [Fig. 12(b)] one can see that the contribution to the lower band comes mainly from $\mathrm{Si} s$ states, while the higher band consists mainly of $p$ states with a modest mixing in of $s$ states. This can be seen as an indication of a partial hybridization of the Si states resulting in the Si bonding environment being partly covalent. This hybridization can also be identified in the Al DOS [Fig. 13(a)]. Compared to a metallic DOS, ${ }^{12}$ there is a peak concentration of $s$ states with mixed- in $p$ states slightly below $0 \mathrm{Ry}$, resembling the $L_{1}$ lobe of a covalent DOS. However, for both

\section{Bonding Charge Density for 110 Plane Section}

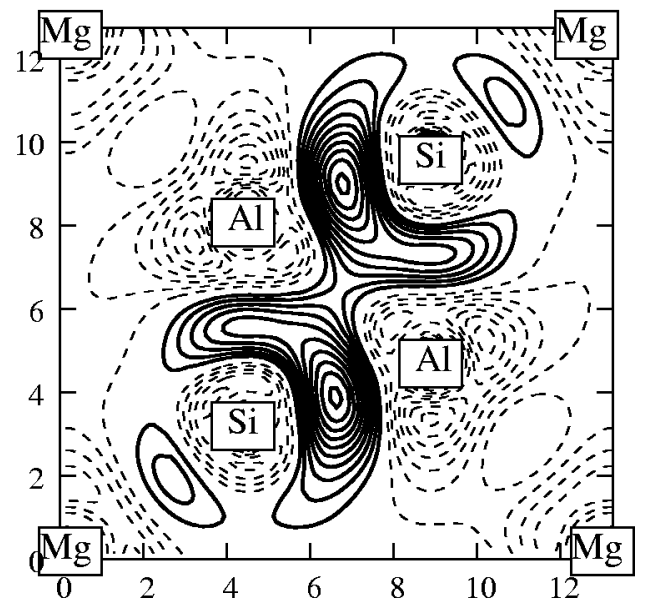

FIG. 11. $U 1$ bonding charge density for the (110) plane. Thick lines represent contour levels with a positive value and thin dashed lines show levels with a negative value. 

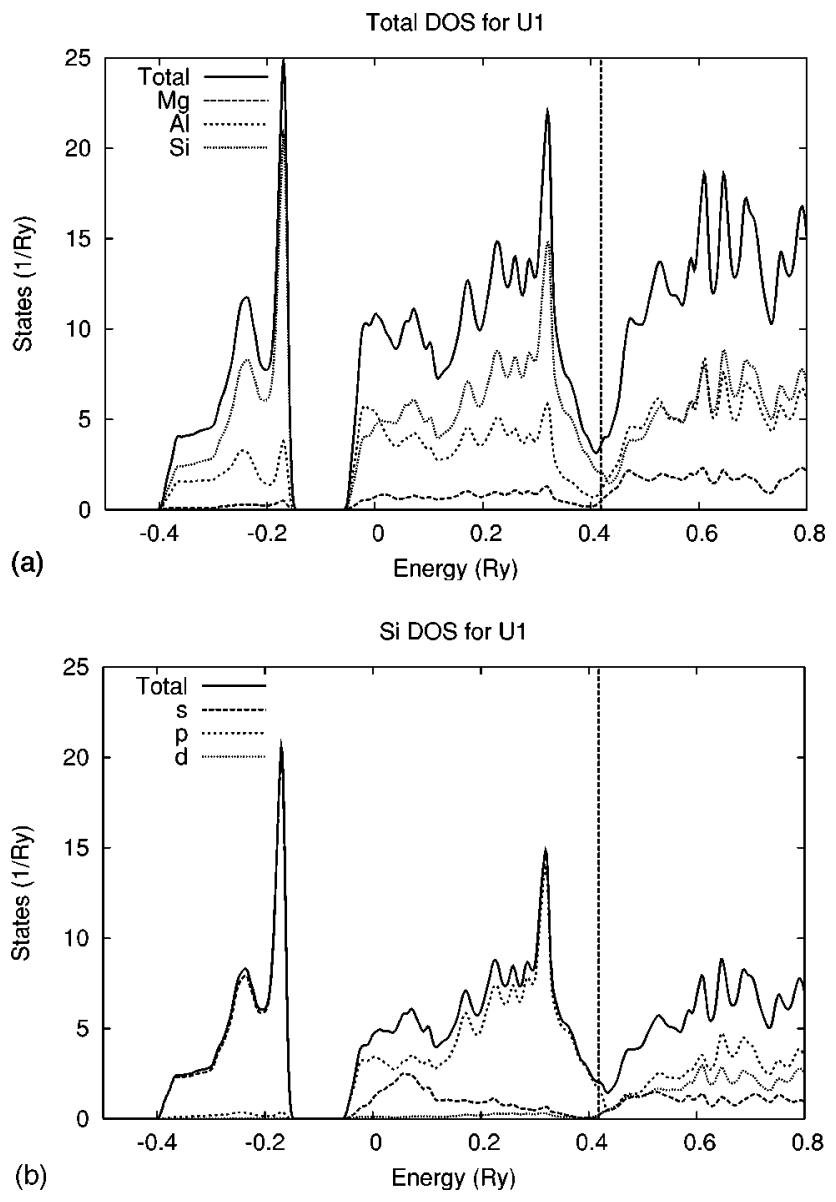

FIG. 12. (a) Total and (b) Si muffin-tin-decomposed densities of states for the $U 1$ phase. Note that the $\mathrm{Al}$ and Si densities of states consists of the contribution from two symmetrically equivalent atoms, while the Mg DOS stems from only one atom. One therefore has to divide by a factor of 2 to get the atomic densities of states for $\mathrm{Al}$ and Si.

$\mathrm{Al}$ and $\mathrm{Mg}$ [Fig. 13(b)], the overall shape of the total atomic DOS seems roughly to follow the square-root relationship characteristic of a metallic DOS.

The origin of the band gap at the center of the occupied states can be understood from the same line of reasoning as that for the $\beta$ phase. In the $U 1$ phase, the $\mathrm{Si}$ atoms are arranged as an hep lattice with lattice parameters $a$ $=4.05 \AA$ and $c=6.74 \AA$. If we once again consider only the Si system (with a nearest-neighbor distance of $4.05 \AA$ ), then little hybridization of the atomic $\mathrm{Si} s$ and $p$ valence states can be expected and a similar DOS to the $\beta$ is seen. That is, the occupied valence states will be separated into two relatively narrow bands. By introducing the $\mathrm{Al}$ and $\mathrm{Mg}$, the $\mathrm{Al}$ forms a tightly bound bonding network with the silicon via the donation of charge from the $\mathrm{Mg}$ atoms. This coupling results in a broadening (with respect to the artificial $\mathrm{Si}$ substructure) of the two occupied bands and the removal of the band gap seen in $\beta$. This has its origins in the stronger mixed $s$ and $p$ character of the second occupied band (centered at $\approx-0.2$ Ry) of Si [Fig. (12(b)], when compared to the strong $p$ character of the corresponding band for $\beta$ (Fig. 4), indicating strong hybridization between the $\mathrm{Si} p$ states and the Al $s$ and $p$ states.
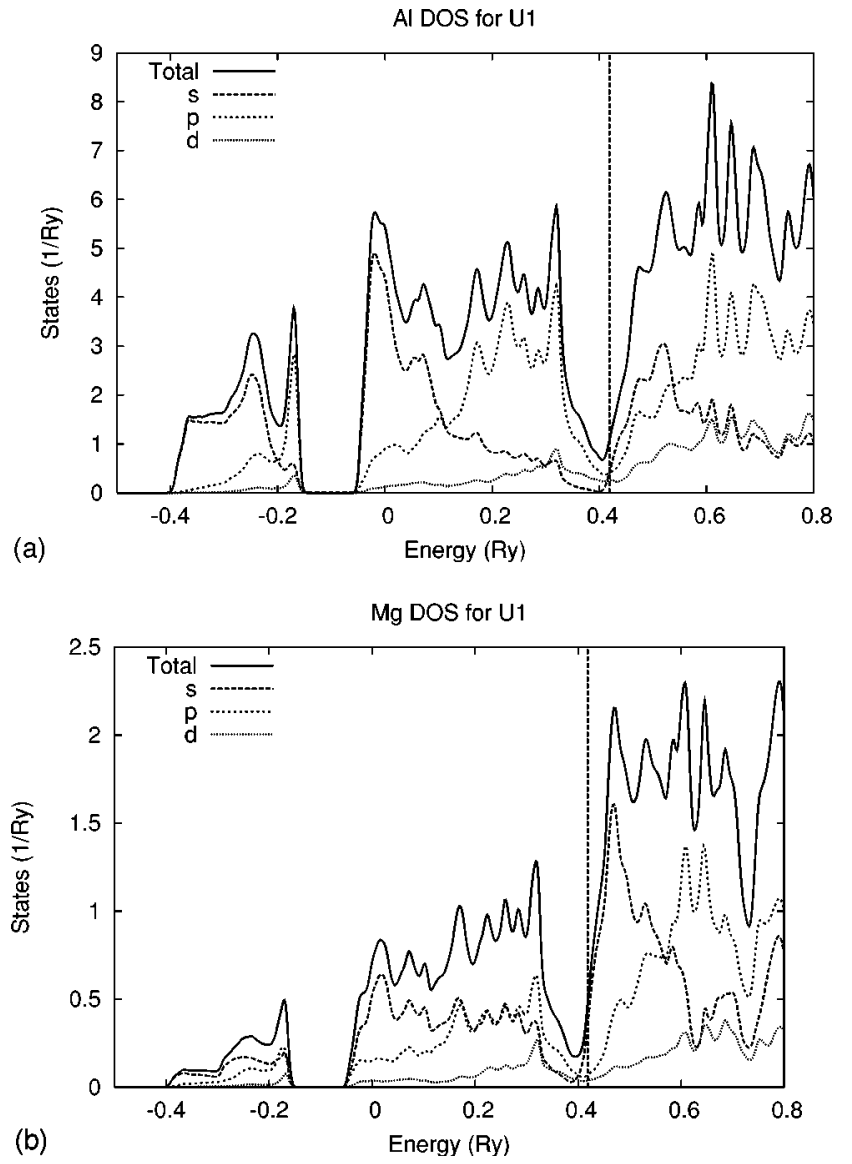

FIG. 13. (a) $\mathrm{Al}$ and (b) Mg muffin-tin-decomposed densities of states for the $U 1$ phase.

B. $\boldsymbol{U} 2$

The $U 2$ primitive/conventional unit cell is orthorhombic (space group $P n m a$ ) with experimentally derived lattice parameters $a=6.75 \AA, b=4.05 \AA$, and $c=7.94 \AA$. It contains four $\mathrm{Mg}$, four $\mathrm{Al}$, and four $\mathrm{Si}$ atoms giving the formula $\mathrm{Mg}_{4} \mathrm{Al}_{4} \mathrm{Si}_{4}$ (Fig. 14). The coordinates of the symmetrically inequivalent atoms of the unit cell are shown in Table III. The morphology and size of the precipitate formed by the $U 2$ phase is usually the same as those for the $U 1$ phase. The $\langle 100\rangle$ direction of the unit cell is oriented parallel to the $\langle 310\rangle$ direction of the fcc $\mathrm{Al}$ matrix. ${ }^{10}$ By performing a volume relaxation of the unit cell, we get an equilibrium volume differing by less than $1 \%$ from the experimentally derived unit-cell volume. A second-order Birch fit gives a bulk modulus of $69.1 \mathrm{GPa}$, very close to the value obtained for the $U 1$ phase.

The $U 2$ phase is similar to the TiNiSi structure type. ${ }^{27,28}$ As for the $U 1$ phase, the bonding in the $U 2$ phase is characterized by the electropositive $\mathrm{Mg}$ atoms donating charge to the electronegative $\mathrm{Al}$ and $\mathrm{Si}$ atoms forming a tightly bound bonding network (Fig. 15). However, unlike for the $U 1$ phase, the electropostitive $\mathrm{Mg}$ atoms retain a large amount of charge and (using a simple chemical picture) there is not enough transfer for the electronegative elements to fulfill the octet rule. ${ }^{28}$ The Al-Si bond lengths are all 2.59 to $2.61 \AA$, while the bond lengths of the $\mathrm{Mg}$-Si neighbor coupling is 2.78 and $2.86 \AA$. 


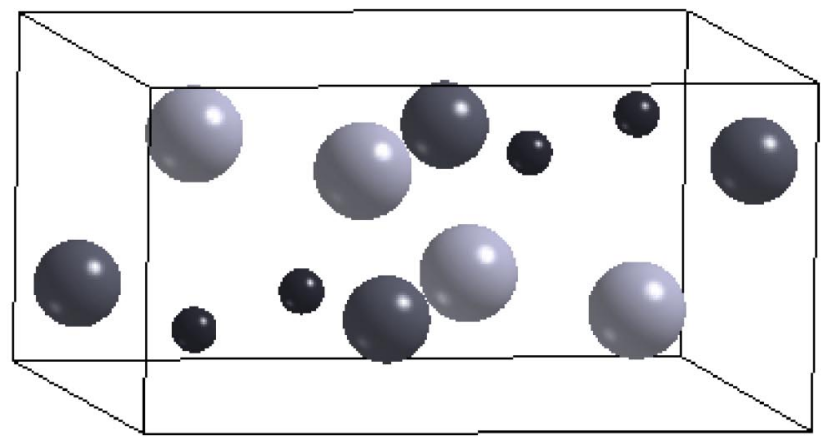

(a)

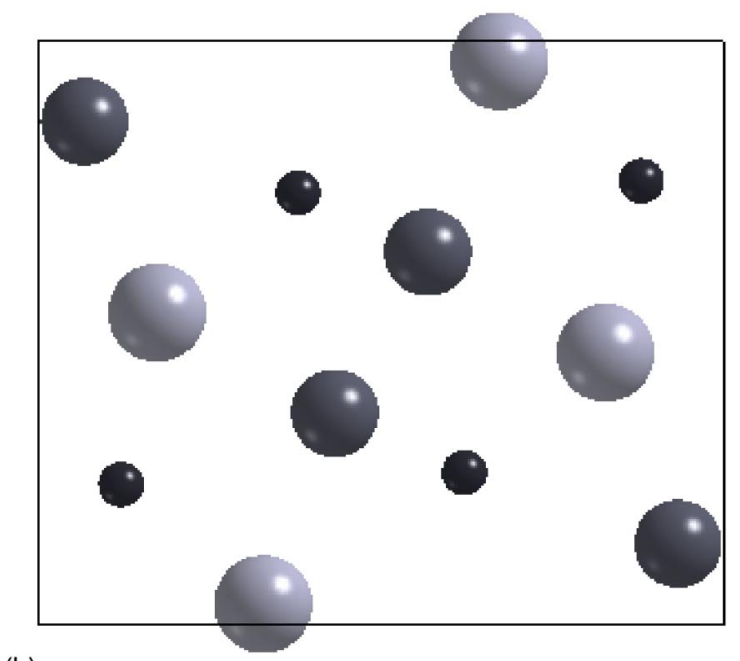

(b)

FIG. 14. U2 conventional unit cell in the (a) perspective and (b) $\langle 010\rangle$ direction.

Figure 16 displays the bonding charge density maps for the (040), (020), and ( $0 \overline{4} 0)$ planes of the $U 2$ unit cell. As for the $U 1$ phase, there is a concentration of charge between $\mathrm{Al}$ and Si nearest neighbors making up the AlSi bonding network. This charge concentration appears to have more of a covalent, directional character than that of the $U 1 \mathrm{Al}-\mathrm{Si}$ bond. Furthermore, one can identify a more pronounced charge concentration between $\mathrm{Mg}$-Si neighbors than for that of the $U 1$ phase. This fits well with the general assumption for this structure class-that a large amount of $\mathrm{Mg}$ charge is retained. As for the $U 1$ phase there is no indication of charge buildup between $\mathrm{Al}$ and $\mathrm{Mg}$ neighbors, indicating that the AlSi network is mainly coupled to the $\mathrm{Mg}$ atoms via the $\mathrm{Si}$ atoms.

TABLE III. Fractional coordinates for the inequivalent atomic positions of the $U 2$ phase unit cell (Ref. 10).

\begin{tabular}{lccc}
\hline \hline Atom & $a$ & $b$ & $c$ \\
\hline $\mathrm{Mg}$ & $0.034(9)$ & $3 / 4$ & $0.327(4)$ \\
$\mathrm{Al}$ & $0.361(4)$ & $1 / 4$ & $0.432(5)$ \\
$\mathrm{Si}$ & $0.239(3)$ & $1 / 4$ & $0.120(9)$ \\
\hline \hline
\end{tabular}

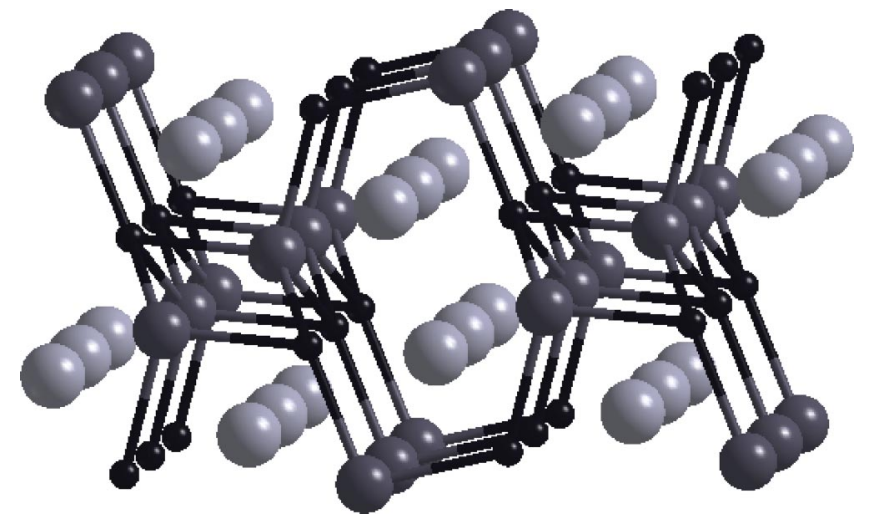

FIG. 15. U2 bonding network.

This picture is further justified by the total and partial densities of states shown in Figs. 17 and 18. Comparing the DOS of the $U 2$ phase with the DOS of the $U 1$ phase one can identify several common features, supporting the proposition that the electronic bonding picture is very similar for the two phases. Note that the total DOS is the sum of one $\mathrm{Mg}$, one $\mathrm{Al}$, and one $\mathrm{Si}$ atom, as opposed to one $\mathrm{Mg}$, two $\mathrm{Al}$, and two $\mathrm{Si}$ atoms for the $U 1$ phase [Fig. 12(a)]. From the atom decomposed DOS of the $U 2$ phase [Fig. 17(a)] one can see that the $\mathrm{Al}$ and $\mathrm{Si}$ states are dominating with respect to the $\mathrm{Mg}$ states, and that the Si states give a slightly larger contribution than do the $\mathrm{Al}$ states. This is consistent with the donation of charge from $\mathrm{Mg}$ to $\mathrm{Al}+\mathrm{Si}$ atoms, as in the case of $U 1$. However, the Mg DOS gives a larger contribution to the total DOS than that for the $U 1$ phase. This is an indication that there is less $\mathrm{Mg}$ to $\mathrm{Al}$ and $\mathrm{Si}$ charge transfer than for the $U 1$ Zintl-type phase. We remind the reader that it is difficult to quantify the charge transfer because the (L)APW $+(10)$ method does not use an atomic/localized basis set. Furthermore, the magnitude of the band gap separating the two occupied bands is slightly smaller for the $U 2$ phase than for the $U 1$ phase (0.075 Ry vs 0.1 Ry for the $U 1$ phase). Consequently, the region of hybridization around $0 \mathrm{Ry}$ is increased for the Al and Si densities of states [Figs. 18(a) and 18(b)] consistent with the pronounced covalent character of the Al-Si bonds found in the bonding charge density. As for the $U 1$ and $\beta$ phases, the origin of the band gap in the occupied states can be explained by the separation of the Si atoms with respect to each other, which for this structure forms a slightly distorted hcp structure (not shown here) with lattice parameters comparable to those of the $U 1 \mathrm{Si}$ hcp sublattice.

\section{DISCUSSION AND CONCLUDING REMARKS}

We have made a comparative study of the electronic structure of the $\beta, \beta^{\prime \prime}, U 1$, and $U 2$ phases in the Al-Mg-Si alloy precipitation sequence. The bonding in the $\beta$ phase is characterized by the covalent bonding between Si-Si nearestneighbor pairs and ionic/covalent bonding between $\mathrm{Si}-\mathrm{Mg}$ nearest-neighbor pairs. For the $\beta$ phase the bonding is dominated by the partly ionic $\mathrm{Mg}$-Si bond. By calculating the heat of formation for the various precipitate phases further insight can be gained into the observed precipitation sequence. Presently we employ the formula 
Bonding Charge Density for 040 Plane Section

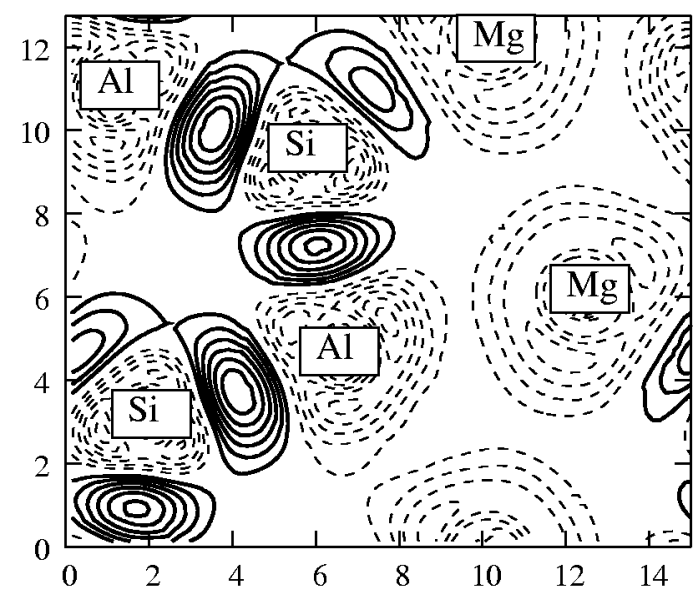

(a)

Bonding Charge Density for 020 Plane Section

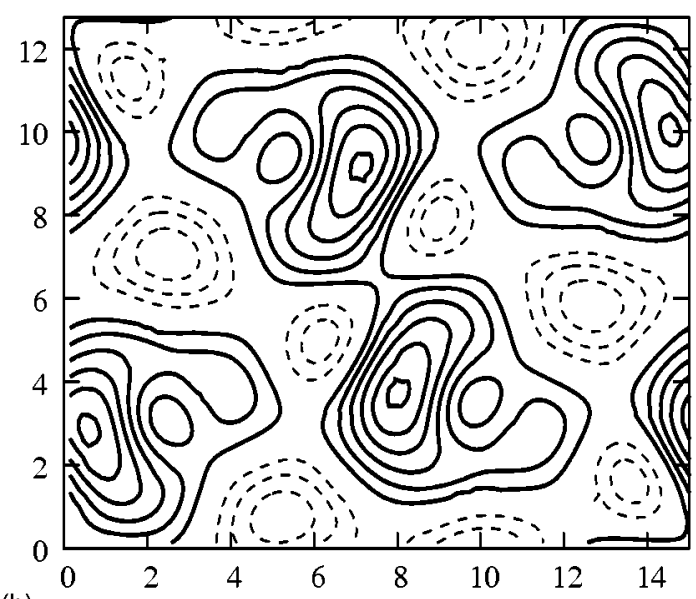

(b)

Bonding Charge Density for 0-40 Plane Section

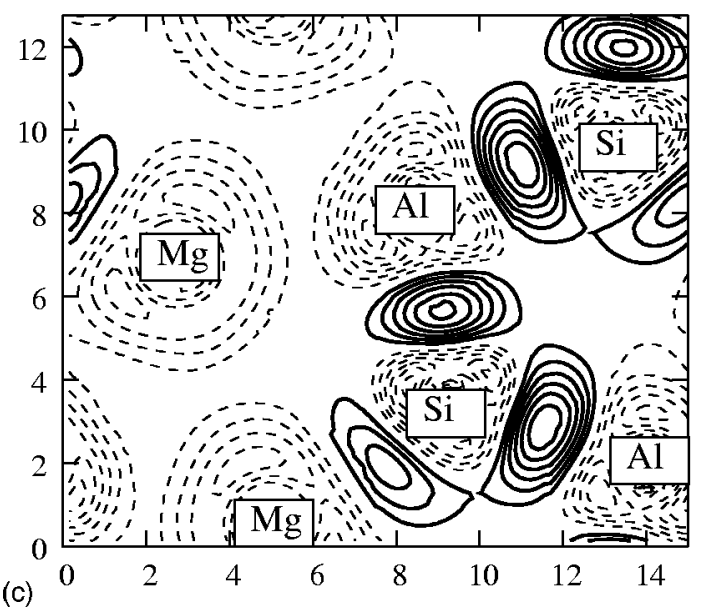

FIG. 16. Bonding charge density for the (a) (040) plane, (b) (020) plane, and (c) $(0 \overline{4} 0)$ plane of the $U 2$ unit cell. Thick lines represent contour levels with a positive value and thin dashed lines show levels with a negative value.
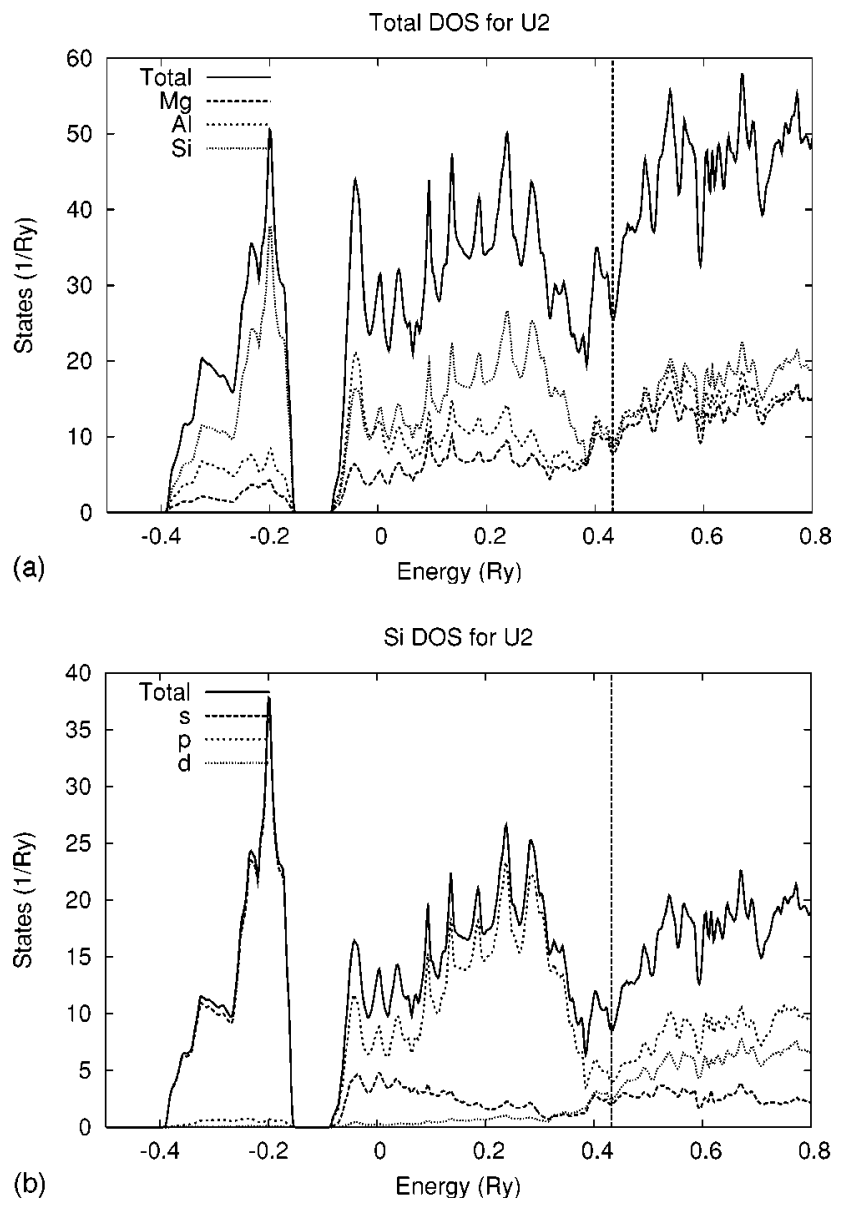

FIG. 17. (a) Total and (b) Si muffin-tin-decomposed densities of states for the $U 2$ phase.

$$
\Delta H=E_{\mathrm{AlMgSi}}-x_{\mathrm{Mg}} E_{\mathrm{Mg}}-x_{\mathrm{Si}} E_{\mathrm{Si}}-x_{\mathrm{Al}} E_{\mathrm{Al}},
$$

where $\Delta H$ is the formation energy/enthalpy per atom; $E_{\mathrm{AlMgSi}}$ is the energy of the given Al-Mg-Si compound; and $E_{\mathrm{Mg}}, E_{\mathrm{Si}}$, and $E_{\mathrm{Al}}$ are the equilibrium ground-state (zerotemperature) energies per atom of hcp $\mathrm{Mg}$, diamond cubic $\mathrm{Si}$, and fcc $\mathrm{Al}$, respectively. $x_{i}$ is the relative content of element $i$ in the compound. Results for the various phases in the precipitation sequence are shown in Table IV and Fig. 19. For the $\beta$ and $\beta^{\prime \prime}$ phases we used the experimentally observed lattice parameters. For the $\beta^{\prime \prime}$ we used the relaxed coordinates found from force minimization (Table I). We have also included the corresponding energy from a past model for the $\beta^{\prime}$ phase proposed by Matsuda et al. ${ }^{8}$

It is difficult to draw any quantitative conclusions based on the relative formation energy of these phases in aluminum, at finite temperatures, without taking into account the effects of the interface and entropy. The calculated energies are nonetheless very reasonable. As can be seen, only three phases $(\beta, U 1$, and $U 2)$ give a negative formation energy. The $U 1$ and $U 2$ are lower in energy than $\beta^{\prime \prime}$, but higher than the $\beta$ phase. $\beta$ shows the most negative energy, which is in line with expectations, since it is the terminal equilibrium structure of the precipitation sequence. The energy of $\beta^{\prime \prime}$ is slightly positive, but not markedly different from $\beta, U 1$, and 

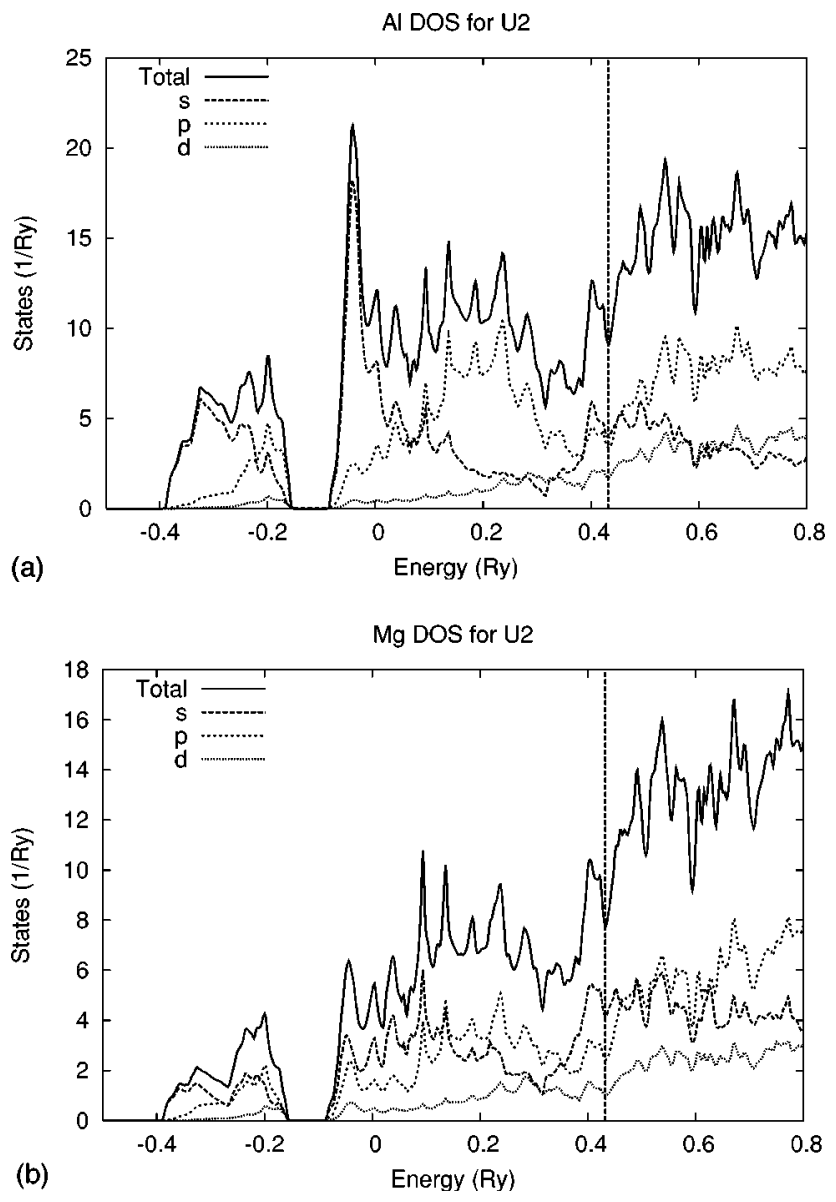

FIG. 18. (a) $\mathrm{Al}$ and (b) Mg muffin-tin-decomposed densities of states for the $U 2$ phase.

$U 2 . \beta^{\prime \prime}$, which can be derived from an fcc supercell, forms early in the precipitation sequence at temperatures above $150^{\circ} \mathrm{C}$, but gradually disappears after further heat treatment. ${ }^{4}$

We note the unusually high heat of formation for Matsuda's $\beta^{\prime}$ model which has a hexagonal unit cell with space group $P \overline{6} 2 m$ with experimentally derived lattice parameters $a=b=4.05 \AA$ and $c=6.74 \AA$, and the stoichiometry $\mathrm{Mg}_{2} \mathrm{Si}$. For the calculated formation energy, we used the experimentally derived lattice parameters and published coordinates. Upon volume relaxation, we found, however, that the structure reduced in volume by $26 \%$, corresponding to a heat of

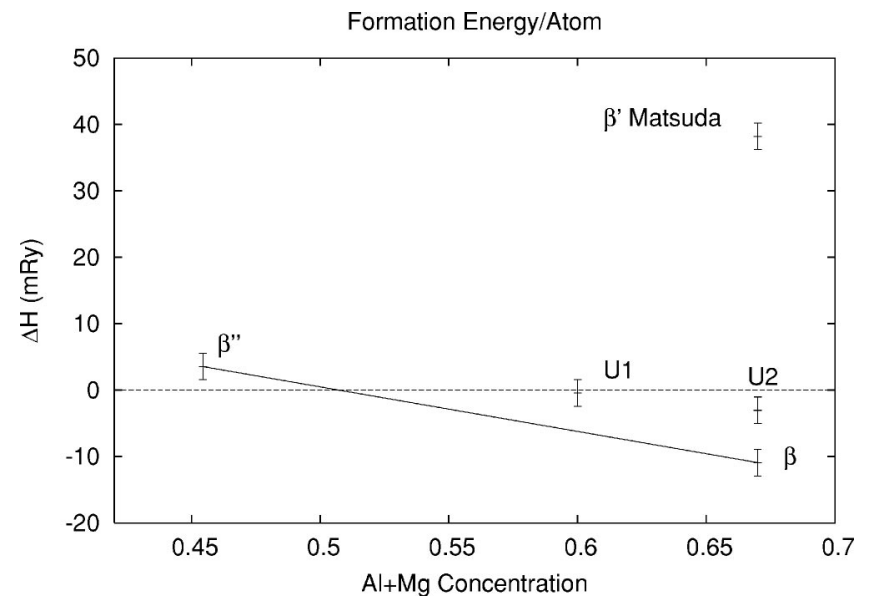

FIG. 19. Calculated energies of formation for the various precipitate phases. The error bars indicate the estimated level of accuracy of $\pm 2.0 \mathrm{mRy}$. The line connecting $\beta^{\prime \prime}$ and $\beta$ is a guide to the eye.

formation of $25 \mathrm{mRy}$. Furthermore, from a second-order Birch fit, we find that for the experimental lattice constant, the Matsuda's $\beta^{\prime}$ phase is under a negative pressure of approximately $6.9 \mathrm{GPa}$. Since the experimentally derived unitcell parameters are regarded as being extremely accurate it becomes difficult to see how such as phase might exist within the $\mathrm{Al}$ matrix.

To this date $U 1$ and $U 2$ are the only phases in the precipitation sequence of the Al-Mg-Si alloy system containing aluminum in addition to magnesium and silicon. The crystallographic structure type of both phases belongs to structure families containing an abundance of documented compounds. A characteristic of both phases is the formation of a tightly bound network of $\mathrm{Al}$ and $\mathrm{Si}$ atoms made possible by charge transfer from the electropositive $\mathrm{Mg}$ atoms. Considering the wide range of structures belonging to this family it is possible that these these type of structures containing other hardening elements than $\mathrm{Mg}$ and $\mathrm{Si}$ would form stable precipitates in aluminum alloys. For example, it is quite remarkable that the $U 1$ phase with magnesium replaced by the rareearth element europium produces a $\mathrm{CaAl}_{2} \mathrm{Si}_{2}$-type structure with lattice parameters and coordinates differing from the $U 1$ phase by only few percent. ${ }^{29}$ Suggested further work includes the calculations on these two phases with isovalent species substituted for the $\mathrm{Si}$ and $\mathrm{Mg}$ sites. In the future these

TABLE IV. Calculated formation energies and bulk moduli. Space groups are given with space-group number in parentheses.

\begin{tabular}{|c|c|c|c|c|c|}
\hline $\begin{array}{l}\text { Structure } \\
\text { type }\end{array}$ & $\begin{array}{l}\text { Space } \\
\text { group }\end{array}$ & $\begin{array}{c}\mathrm{Al}: \mathrm{Mg}: \mathrm{Si} \\
\text { in unit cell }\end{array}$ & $\begin{array}{c}\text { Lattice } \\
\text { parameters }(\AA)\end{array}$ & $\begin{array}{c}\text { Bulk modulus } \\
\text { (GPa) }\end{array}$ & $\begin{array}{c}\text { Energy/atom } \\
\text { (mRy) }\end{array}$ \\
\hline$\beta^{\prime \prime}$ & $C 2 / m(12)$ & $0: 5: 6$ & $a=15.16, b=6.74, c=4.05$ & 65 & 3.53 \\
\hline$\beta$ & $F m \overline{3} m$ & $0: 4: 2$ & $a=b=c=6.39$ & 54 & -10.93 \\
\hline$\beta^{\prime}$ Matsuda $^{\mathrm{b}}$ & $P \overline{6} 2 m$ & $0: 4: 2$ & $a=b=7.1, c=4.05$ & NA & 38.174 \\
\hline$U 2$ & $P \overline{3} m 1$ & $4: 4: 4$ & $a=b=4.05, c=6.74$ & 69 & -3.04 \\
\hline$U 1$ & Pnma (62) & $2: 1: 2$ & $a=6.75, b=4.05, c=7.94$ & 71 & -0.45 \\
\hline
\end{tabular}

${ }^{\mathrm{a}}$ Reference 5 .

${ }^{\mathrm{b}}$ Reference 8 . 
calculations could also be used together with interfacial energies and entropy calculations to estimate the solid solubility of these phases in aluminum.

Furthermore, the rule of thumb that successful aluminum precipitation hardened alloys have secondary and ternary elements that are larger and smaller than aluminum is not sufficiently accurate when applied to the stability of bulk phases in the precipitation sequence. The atomic radii of $\mathrm{Al}, \mathrm{Si}$, and $\mathrm{Mg}$ vary with the bonding environment. For example, in the equilibrium $\beta$ phase the atomic size of $\mathrm{Si}$ is increased and that of $\mathrm{Mg}$ correspondingly decreased during formation of a dominating ionic/covalent $\mathrm{Mg}$-Si bond. Also, using the appropriate values for ionic radii, ${ }^{12}$ the $\mathrm{Mg}$-Si bond lengths in the $\beta$ and $\beta^{\prime \prime}$ phases are predicted to be considerably smaller than what the present calculations show. A more precise for-

*Email address: Anders.Froseth@phys.ntnu.no

${ }^{1}$ D.A. Porter and K.E. Easterling, Phase Transformations in Metals and Alloys, 2nd ed. (Chapman and Hall, London, 1997).

${ }^{2}$ M. Murayama and K. Hono, Acta Mater. 47, 1537 (1999).

${ }^{3}$ G.A. Edwards, K. Stiller, G.L. Dunlop, and M.J. Couper, Acta Mater. 46, 3893 (1998).

${ }^{4}$ C.D. Marioara, S.J. Andersen, J. Jansen, and H.W. Zandbergen, Acta Mater. 49, 321 (2001).

${ }^{5}$ H.W. Zandbergen, S.J. Andersen, and J. Jansen, Science 277, 1221 (1997).

${ }^{6}$ P.M. Derlet, S.J. Andersen, C.D. Marioara, and A. Froseth, J. Phys.: Condens. Matter 14, 4011 (2002).

${ }^{7}$ M. Takeda, F. Ohkubo, T. Shirai, and K. Fukui, J. Mater. Sci. 33, 2385 (1998).

${ }^{8}$ K. Matsuda, V. Sakaguchi, V. Miyata, V. Uetani, T. Sato, A. Kamio, and S. Ikeno, J. Mater. Sci. 35, 179 (2000).

${ }^{9}$ S.J. Andersen, C.D. Marioara, A. Froseth, R. Vissers, and H. Zandbergen (unpublished).

${ }^{10}$ S.J. Andersen, C.D. Marioara, A. Froseth, R. Vissers, and H. Zandbergen (unpublished).

${ }^{11}$ N. Ryum, Aluminium Alloys: Their Physical and Mechanical Properties (Engineering Materials Advisory Service, Sheffield, U.K., 1986), Vol. III.

${ }^{12}$ C. Kittel, Introduction to Solid State Physics, 7th ed. (Wiley, New York, 1996).

${ }^{13}$ P. Blaha, K. Schwarz, G. Madsen, D. Kvasnicka, and J. Luitz, Computer code WIEN2K, An Augmented Plane Wave and Local Orbitals Program for Calculating Crystal Properties (Karlheinz Schwarz, Technical Universitat, Wien, Austria, 1999). mulation would involve the ability of the secondary $(A)$ and ternary $(B)$ elements to form stable bonds $(A-B, A-A$, and $B-B$ ) with bond lengths which are comparable that of the Al-Al bond.

\section{ACKNOWLEDGMENTS}

This study has been performed as part of the research programs "KMB Heat Treatment Fundamentals" and "SUP Microstructure and Nanostructure Based Materials Development," supported by the Norwegian Research Council and collaborators from the industry. Parts of this work have been supported by the Norwegian Research Council through CPU time on the NOTUR Origin 3800.

${ }^{14}$ E. Sjostedt, L. Nordstrom, and D.J. Singh, Solid State Commun. 114, 15 (2000).

${ }^{15}$ J.C. Slater, Adv. Quantum Chem. 1, 35 (1964).

${ }^{16}$ G.K.H. Madsen, P. Blaha, K. Schwarz, E. Sjostedt, and L. Nordstrom, Phys. Rev. B 64, 195134 (2001).

${ }^{17}$ P.E. Blochl, O. Jepsen, and O.K. Andersen, Phys. Rev. B 49, 16223 (1994).

${ }^{18}$ J.P. Perdew, S. Burke, and M. Ernzerhof, Phys. Rev. Lett. 77, 3865 (1996).

${ }^{19}$ P. Baranek, J. Schamps, and I. Noiret, J. Phys. Chem. B 101, 9147 (1997).

${ }^{20}$ P. Baranek, J. Schamps, and I. Noiret, J. Phys. Chem. B 103, 2601 (1999).

${ }^{21}$ D.M. Wood and A. Zunger, Phys. Rev. B 34, 4105 (1986).

${ }^{22}$ E. Anastassakis and J.P. Hawranek, Phys. Rev. B 5, 4003 (1972).

${ }^{23}$ D.A. Papaconstantopoulos, Handbook of Electronic Structure of Elemental Solids (Plenum, New York, 1986).

${ }^{24} \mathrm{O}$. Madelung, in Numerical Data and Functional Relationships in Science and Technology, Landolt-Börnstein, New Series, Group III, Vol. 17, Pt. e (Springer-Verlag, Berlin, 1983).

${ }^{25}$ A.Y. Liu, K.J. Chang, and M.L. Cohen, Phys. Rev. B 37, 6344 (1988).

${ }^{26}$ C. Cheng, R. Hoffman, R. Nesper, and H. von Schnering, J. Am. Chem. Soc. 108, 1876 (1986).

${ }^{27}$ G. Nuspl, J. Evers, G.A. Landrum, and R. Hoffman, Inorg. Chem. 35, 6922 (1996).

${ }^{28}$ G.A. Landrum, R. Hoffman, J. Evers, and H. Boysen, Inorg. Chem. 37, 5754 (1998)

${ }^{29}$ P. Schobinger-Papamantellos and F. Hulliger, J. Less-Common Met. 146, 327 (1989). 